\title{
Maritime Spare Parts Management: Current State-of-the-Art
}

\author{
Julia Pahl \\ Department of Technology and Innovation, University of Southern Denmark \\ julp@iti.sdu.dk
}

\begin{abstract}
Having the right spare part at the right time to the right place for ship maintenance to the minimal possible costs is an exigent management problem that maritime shipping companies face. This is especially challenging in bulk shipping where routes are not fixed, but subsequent port calls depend on spot market dynamics. Thus, spare parts allocation ahead in time is limited, but possible if failures rates of ship components and their timing can be foreseen, so that spare parts can be allocated to hedge against the risk of long waiting times and thus ship downtimes. Companies are very sensitive to the latter due to significant ship operational costs that accrue also during downtime, but without revenues. Thus, reducing ship downtimes by monitoring the condition of components key to the ships performance is essential to the task. However, shipping companies seem far away from applying sophisticated methods for forecasting and planning due to various challenges ranging from data gathering and cultivating an understanding of data quality needs, adaptation to move from preventive towards predictive and condition-based maintenance (CBM) thus enabling the introduction and application of decision support tools for demand forecasting, sourcing, spare parts allocation, and inventory management. In this paper, we investigate the current state of the art of spare parts logistics (SPL) management tightly related to CBM for maritime shipping and discuss the application of methods to the bulk carriage market.

Keywords: maritime spare parts management, maintenance planning, bulk carriage market, survey, guidelines
\end{abstract}

\section{Introduction}

Maritime transport accounts for $80 \%$ of the world merchandise trade volume with dry cargo accounts for over two thirds of total maritime trade volumes where the greatest share is on main bulk, tanker trade, and other dry cargo [34]. Bulk shipping entails the transportation of raw materials for heavy industry, e.g., iron ore, coal, oil, and the like [26]. It takes place on markets with "perfect competition" where prices reflect all available information and directly adjusts to new information [26] and shipping companies are freight rates/price takers. Voyage contracts in bulking are usually negotiated on a short time horizon, i.e., between days and weeks, before loading the cargo [22]. They can be time-based or voyage-based where a ship owner either leases the ship for a certain time period [26] or for a certain voyage formed by a sequence of ports. Thus, routes and schedules are not fixed, but determined on a short time scale [35]. On such markets, operational efficiency becomes a significant factor of survival for shipping companies [26] where capital costs are one of the main drivers. A significant portion of total costs pertains to maintenance actions and related SPL [9].

Maritime SPL management deals with the process of procuring, allocating, and controlling components of ship parts to keep the ship in such safe condition [20] as required by safety rules and regulations [7, $13,14,35]$. Ship maintenance is typically performed in a failure-preventive form to minimize unexpected downtime risks [13] leading to very conservative maintenance intervals which require high spare parts inventory levels [32, 35]. But as ships are usually operated in harsh environments, unexpected failures can occur [27, 32]. Downtimes whatever their cause lead to severe revenue losses that are endured and need to be covered by the company which render them very sensitive to that topic [27]. Thus, better failure prediction techniques for critical parts and components as well as their alloction in terms of time and place are required [27] to avoid high operational costs due to emergency maintenance actions in the first place.

The integration of SPL, inventory management, as well as maintenance planning and scheduling has not achieved full attention of the research community [14, 35]. This is especially true in maritime (bulk) shipping which is surprising considering its importance and share 
in maritime trade volumes [34].

We provide an overview of the problem area and a state-of-the art survey of maritime SPL, discuss the challenges companies face when aiming at optimizing SPL, and give guidance to what needs to be in place to achieve cost-effective SPL. ${ }^{1}$ We focus on maritime shipping further taking into account related areas that influence SPL. We also regard literature dealing in general with SPL wherever it is suitable, but do not provide a comprehensive analysis on the literature of SPL or ship maintenance planning. We list our main findings regarding the literature analysis in Table 1.

\section{Maritime Maintenance}

Maintenance and related service logistics are a great portion of operational costs for shipping companies [9]. According to [33], 25-35\% of an operator's direct operating costs are maintenance-related. This is expected to increase as more and more ships in the wear-out phase are kept operational $[2,26]$.

\subsection{Areas of Maintenance and Repair}

There are various components and systems that need to be taken into account when considering maritime maintenance planning. Ships themselves and their equipment are quite complex in terms of technical requirements and system components.Areas of a bulk ship subject to maintenance encompass 1) the ship hull, 2) ship specific equipment, e.g., cranes, 3) navigation and communication equipment, 4) radar and search lights, 5) other electric equipment, 6) crew specific equipment, e.g., galley or cabin equipment, and 7) propeller and main engine $[9,33]$. The major part of the literature on SPL concentrates on main engine related parts and components.

\subsection{Types of Maintenance Actions}

We can distinguish between maintenance where the ship is still in use, named routine maintenance and where the ship is unavailable, named periodic maintenance; see [33]. Routine maintenance accounts for $14 \%$ of the operational ship costs [29]. These include, e.g., maintaining the main engine and auxiliary equipment, superstructure painting, steel renewals with save access as these actions are done during ship operation [29]. Periodic maintenance renders the ship unavailable for use and takes place in dry-docks [29]

\footnotetext{
${ }^{1}$ The work of this paper relates to the Shipping Lab project "Digital vessel operation". The funding of the project is provided by the InnovationFund Denmark (IFD) under File No. 8090-00063B, Danish MaritimeFund, Lauritzen Fonden and Orient's Fond, Denmark.
}

performing major repairs, e.g., ship hull or main engine overhaul. Special surveys guide the work [9].

\subsection{Maintenance Strategies}

Maintenance strategies can be divided into a) corrective (synonymous with reactive or failure-based), b) preventive, c) condition-based, and d) predictive maintenance (see also [17]). This list can be enriched by e) opportunistic maintenance [1] which combines preventive and corrective maintenance by considering neighboring parts, items, or system components which (may) depend on each other in order to reduce the risk of earlier failure due to these neighboring components. Opportunistic maintenance has been proposed for the maritime sector in $[8,10]$.

As mentioned above, in the wear-out phase, the reliability of components is different from that after previous maintenance. Thus, maintenance policies should be determined according to the ship age. However, applying, e.g., corrective maintenance bears the risk of unexpected failures that can lead to expensive logistics and significant ship downtimes [32] while preventive maintenance policies can lead to over-maintained ships encompassing unnecessary, too early performed maintenance actions including premature and expensive spare parts exchange and frequent inspections [33]. For that reason, a CBM strategy helps lowering the uncertainty about failure events while it provides companies with a greater time frame to allocate spare parts where they are needed. Physical monitoring techniques include, e.g., vibration analysis, acoustic emissions, ultrasonic testing implementations, oil analysis, strain measurement, electrical effects, shock pulse method, radio-graphic inspection, and thermo-graphic monitoring technology [18]. Applying CBM, it is possible for companies to balance the costs of premature exchange of parts and the risk of failure in remote locations. The art of efficient spare parts allocation is to take advantage of forecasting methods for failure rates and component demand and chose wisely the inventory control strategy that leads both to low spare parts inventory and logistics costs and accomplished service levels.

\subsection{Maritime Maintenance Planning}

The process of maintenance planning begins with structuring and scheduling the overall maintenance cycles according to legislation in parts guided by surveys when the ship is in dry dock, and company policy [2, 12]. The rules and regulations for the construction and classification of ships of the Nippon Kaiji Kyokai define that all ships are subject to 
annual surveys, docking surveys, and special surveys $[2,12]$. Based on these specific cycles, maintenance scheduling are broken down and specific jobs are determined on a finer time scale, e.g., for each year and month. This work can be supported by information technology (IT)-systems named planned maintenance system (PMS) [13] further discussed in Section 2.6.

\subsection{Spare Parts Logistics Network}

The different ship states as well as the maritime maintenance and SPL network can be depicted as in Figure 1. The figure shows that ships can have three states without taking into account maneuvering or anchoring outside a port which are 1) being in a dry dock, 2) sailing, 3) berthing. The figure also roughly sketches the maintenance inventory network assuming that dry docks are located in ports. The figure abstracts from the various actors that are responsible for the different functions within the network. For instance, central warehouses can be run by multiple parties and serve directly ports or distribution centers that are further responsible for serving multiple ports. Ports also have warehouses that can belong to a shipping company or to suppliers serving multiple shipping companies. The same is valid for the dry dock. These on-shore entities can provide ships with spare parts in a timely fashion if they have the right spare part at the right time available which otherwise needs to be ordered [27]. Spare parts can be delivered to the port and/or docking area or directly to the vessel when the ship is in anchorage or passed the out-port limit.

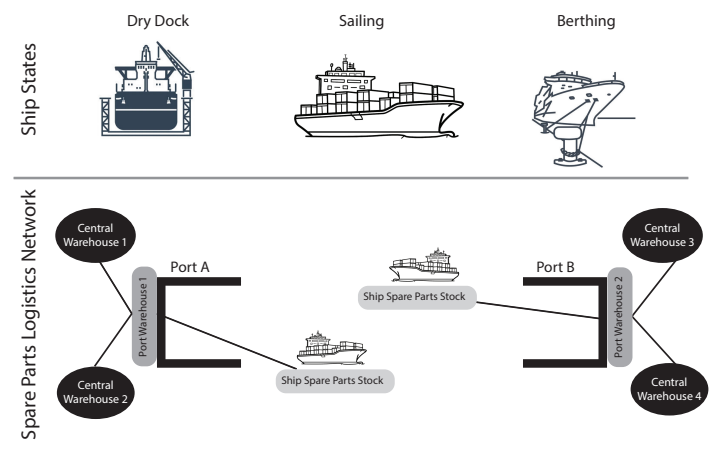

Figure 1. Ship States and Spare Parts Inventory Network; own source

We also find spare parts stocks on ships themselves for safety reasons required by international maritime organization (IMO) [2, 7, 12]. Such on-board safety stocks are limited in space and economic reasons [9], thus they also need careful consideration and planning.

Sourcing and replenishment of spare parts including transportation costs highly depend on the established supplier network and related (long-term) contracts of shipping companies [35] that can include loyalty and/or volume incentive discounts, and delivery fees. Besides, ship designer and equipment manufacturer recommendations regarding spare parts quality also play an important role [35] when it comes to maintenance and spare parts selection (see Section 3.1.2).

\subsection{Supporting Information Technology}

Frequently, PMS are used in shipping companies that determine maintenance intervals based on original equipment manufacturer (OEM)'s specifications and instruction manuals for the components/equipment [35]. Besides, company policy, rules and regulations also from classification societies and vessel's ships flag state further constrain intervals [28].

A great portion of maintenance jobs is performed while sailing. Usually, ships receive a list of maintenance jobs from the administration office and/or they have PMS on-board the ship. Such systems include a systematic inspection schedule aiming at detecting malfunctions before they cause failures [13]. If possible, the completion of jobs is reported back online. However, this requires well-trained personnel [13], user-friendly interfaces of information and communication technology (ICT)-systems to provide and gather correct and comprehensive data [33]. It is also crucial to select relevant and essential information from rich practical expert knowledge of maintenance personnel [13, 33], standardize it, e.g., in code-form, so that it can be stored in databases permitting an efficient communication between ship owner or manager, shipyard, and supplier and allow the determination of robust maintenance plans and schedules [33]. Moreover, relevant correct data allows CBM based on large data sets for aged ships not equipped with sensors to monitor their condition. Anyhow, PMS operations are labor-intensive [13, 33] and planned tasks must be conducted at scheduled times. Theses can be time-based and/or running hour based maintenance tasks [13]. Checklists underlie PMS and those parts that are included in a checklist must be inspected even if there is no (predicted) failure [13]. Inspections must be recorded and kept to meet the requirements of the ISM Code [13].

Research evaluates the potential contributions of "maintenance 4.0" supporting human reliability in ship maintenance using shipboard operation human reliability Analysis (SOHRA) to measure marine-specific human reliability [13]. The case study focuses on a diesel generator maintenance operation. Calculating and comparing the human error probability 
(HEP) against automated maintenance, the study shows that the HEP is significantly reduced using maintenance 4.0 concepts.

\section{State-of-the-Art of Maritime Spare Parts Management}

With reference to the SPL network, we classify and discuss the literature according to the following problem areas: 1) Spare parts inventory management including classification and selection, 2) Joint maintenance and spare parts inventory planning, and 3) Spare parts delivery. We concentrate on the quantitative aspects of the topics. As a result, the literature that we include in our review mainly pertains to operations research, data science, and ICT abstracting from contractual and/or stakeholder issues as well as from technical issues related to the spare parts themselves. To that end, we also exclude issues of single-/multi-structure repair or replacement of spare parts from our analysis.

\subsection{Spare Parts Inventory Management}

Literature reviews on maintenance and service logistics management for shipping are rare [9, 20]. We find one survey [9] that gives a comprehensive review on the various areas named sector characteristics in maritime maintenance, e.g., 1) multi-actor setting, 2) small amount of failure-related data, 3) mandatory surveys in dry docks, 4) system-specific spare parts, 5) multi-echelon structures of inventory holding, 6) multi-indenture systems, 7) moving assets, 8) economic dependency, and 9) long life-cycles as well as sub domains, i.e., a) system design, b) failure prediction / degradation modeling, c) maintenance service contract design, d) maintenance strategy selection, and e) maintenance planning. The review further provides lessons-learned from analyzing the literature and practical experience in a research project with four bulk carriage companies.

3.1.1. Spare Parts Inventory Process Steps Spare parts (inventory) management can be divided into three main steps which are 1) spare parts classification, 2) spare parts forecasting, and 3) spare parts stock control [3].

The process steps that need to be established by shipping companies for their SPL management is depicted in Figure 2. As discussed earlier, SPL is tightly linked to maintenance including company policy and the availability of failure rates and probabilities.

The first question to be answered in this process is which items are critical to ship performance and what

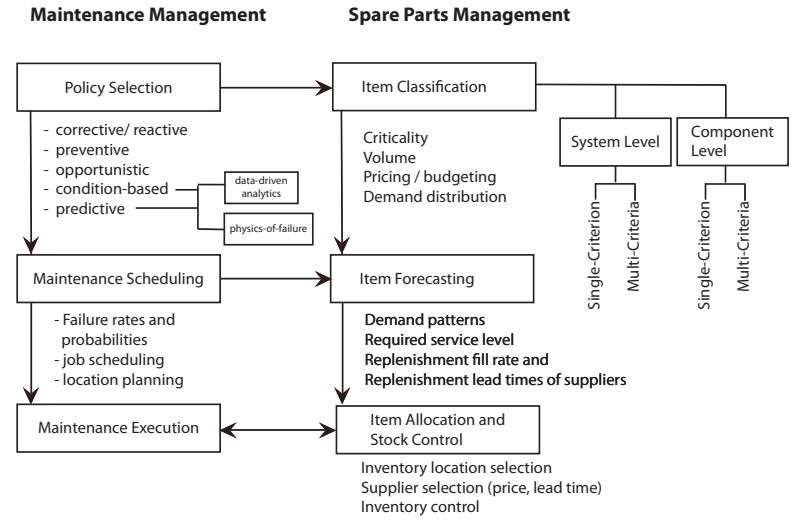

Figure 2. Spare Parts Inventory Planning Process Steps: own source

characteristics render them important to be considered in planning, i.e., which selection criteria need to be applied to identify critical parts, e.g., price or replenishment costs, item quality, replenishment lead time in dependence of the supplier, multiple suppliers availability, just to mention a few. The classification of critical spare parts is a complex issue and we find various single or multi-criterion approaches in the literature as well as considerations regarding the system or component level (see also Section 3.1.2. The second question concerns the quantification of critical spare parts determined by forecasting methods that should be based on failure rates and probabilities of ship components, required service levels, replenishment fill rates, and lead times of suppliers. The third question links tightly to this and is where to allocate critical items, so that maintenance service levels are fulfilled and downtimes of ships minimized. Stock control bases on the replenishment policy of the shipping company agreed with their suppliers and ranges from establishing and maintaining safety stock levels for those parts with low inventory costs but high criticality, e.g., o-rings, to "one-out-one-in" policies in case of critical items with high replenishment and inventory costs, e.g., turbo charger cartridges, which we can report from own experience gained from a research project with five bulk carriers.

3.1.2. Spare Parts Classification Item classification aims at capturing their "real", practical value and role in ship maintenance. For instance, the availability of specific o-rings can be critical for the overall time duration of maintenance as without this item ship performance cannot be re-established. However, item costs are very low, thus mostly applied 
classical $\mathrm{ABC}$ analysis that uses demand value and volume as ranking criteria and fixed service levels per class does not provide satisfactory results.

Most commonly used criteria in the literature are single or multiple criteria approaches using demand value and demand volume [3, 31], stock-out/shortage costs and replenishment lead times [3, 9, 25]. Most popular used criteria especially applied to consumer goods are item costs (unit or inventory costs) as well as part criticality [3]. Others are demand volume, or value, supply characteristics, e.g., replenishment lead time, supplier availability, and risk of non-supply, as well as demand or lead time variability [3]. Less used criteria are part life cycle phase, specificity, or reliability [3]. Moreover, the survey provided in [3] reveals that literature is lacking case studies and experience with practical application at least in the consumer goods industry which the survey deals with, but, based on our experience, we can state that the same is valid for the maritime sector.

Single-Criterion Classification A single item classification criterion that explicitly takes into account item criticality is propsed by [31]. The authors of [36] and [31] are the first to propose approaches from an inventory cost perspective where the latter has the objective to minimize total inventory costs while achieving a required average fill rate over all items or stock keeping units (SKUs). This cost criterion ranks all SKUs based on the value of $\frac{b D}{h Q}$ where $b$ is the criticality of a SKU measured by its shortage costs, $D$ is the demand volume, $h$ is the unit inventory holding cost factor, and $Q$ is the order size. The authors show that this criterion is best used with a fixed cycle service level, e.g., 1-stockout probability, per item class rather than fixed fill rates. The method is compared to traditional criteria proposed, e.g., by [36], using three large real-life data sets where they vary the target average fill rate as well as the number of classes and demonstrate that their criterion outperforms all other methods. However, the method is not specifically designed for maritime SPL.

The inventory optimization model proposed in [20] for on-board ship items uses a criticality threshold $T$ to rank subsystems of a ship to conclude if, in case the threshold is exceeded, the subsystem should be taken into consideration for maintenance actions. The authors divide the ship into three levels being 1) system, 2) subsystem, and 3) item. They further argue that criticality should be linked to the impact of the malfunctioning system the component is part of. They define the criticality value as a multiplication of 1) the efficiency of the system in which the component/subsystem partakes, 2) the efficiency of the whole ship, and 3) the safety [20]. For an item in a subsystem, the criticality value is defined as the subsystem criticality level multiplied by the probability of the item malfunctioning and affecting its subsystem multiplied by $\left(1-A_{j}\right)$ where $A_{j}$ is the item availability defined by the mean time between failures divided by the sum of the mean time between failures, the mean time to repair, and the mean time waiting for spare parts. They further define reliability and availability functions of items. The proposed model balances overall unavailability costs against inventory costs including costs of capital, warehousing, depreciation, insurance, taxation, obsolescence, and shrinkage. The model is solved by a heuristic procedure that is able to best reduce on-board ship inventories. However, their procedure needs to be tested to real practical cases.

Multi-Criteria Classification Many approaches have been proposed using multiple criteria, e.g., certainty of supply, rate of obsolescence, lead time, costs of review and replenishment, design and manufacturing process technology, and substitutability; see [31] and the references therein. Regarding multi-criteria methodologies, we find weighted linear programming, analytical hierarchical processing (AHP), and operations-related groups [31]. They are implemented using, e.g., matrix models, weighted linear optimization, artificial neural networks, weighted Eucledian distances with quadratic optimization, or fuzzy logic (see [3] and the references therein). Besides, qualitative methods are also applied [3]. One method to mention is the "Vital, Essential, Desirable" model based on expert assessment thus prone to subjectivity. These approaches are not specific to maritime spare parts thus related references are not listed in Table 1.

System versus Component Level Prognostic methods for failure are normally designed and applied to the (lowest) component level of a ship [32]. But especially for ships in the wear-out phase, nearby components of the overall system they are partaking may be affected as well. For that reason, it is more reasonable to regard the system level of ship parts [32] and connect prognostics of these components. However, due to the number of components of ship systems, this is infeasible in practice, so that key components need to be selected. For these components, condition-based prognostics of failure rates should be gathered for use in optimization methods for SPL. These can be physics-of-failure based or data-driven analytics derived from large data sets [32]. For the other parts, failure rates can be taken from OEM or 
expert opinion [32]. For instance, the work in [4] deals with CBM for vessel diesel engines using data-driven analytics, i.e., artificial neural networks, to analyze engine performance data.

Critical Part Selection One method to assess component criticality expressed by risk priority number (RPN) is failure mode, effect and criticality analysis (FMECA) [32]. But this method is prone to problems in maritime maintenance as the risk of failure for a component is defined by a combination of frequency and impact. A failure with low probability or frequency of occurrence but with high impact would have the same RPN as a failure with high frequency but low impact. Also, FMECA is an extensive and time-consuming method thus not applicable for a large number of components.

In order to overcome the problem of critical part selection as well as system versus component level consideration, different methods have been proposed; see [32] and the references therein. For instance, the 4-quadrant method plots failures along two axes of failure frequency and failure consequence expressed in terms of costs or ship downtime. Those components with moderate to high impact at moderate to high frequencies should be selected for predictive maintenance [32].

An evaluation system for determining critical weight coefficients of spare parts based on AHP and technique for order of preference by similarity to ideal solution (TOPSIS) is proposed in [30]. TOPSIS is a ranking method to choose alternatives where the selected one should have the shortest geometric distance from the positive ideal solution and the longest from the negative ideal solution [5]. The authors aim at establishing those critical spare parts that should be in the on-board inventory of ships. Their use case is the Chinese Navy and they pre-select five types of electronic spare parts to test their model. Anyhow, they do not provide information regarding the pre-selection process in their case study and thus circumvent the main problem.

A flexible framework for ship structure and machinery equipment inspection monitoring including risk assessments and probabilistic failure case scenario analysis is proposed in [16]. This includes case studies on the performance of the framework for a tanker, a bulk carrier, as well as a container ship.

Spare Part Deteriortation Spare parts are also subject to deterioration as with time their functionality deteriorates [14]. Due to deterioration aspects, on-board spare parts required for the safe and secure ship performance need to be checked and the completeness of these parts assured. Such spare parts need to be taken into account, separately in planning. One reference that regards item deterioration in their model for maintenance scheduling is [2].

\subsubsection{Spare Parts Forecasting Spare parts} forecasting (SPF) deals with the determination of the type, number, and timely availability of spare parts for maintenance actions. Successful SPF is highly dependent of the maintenance policy and the way how failure rates are established, so that SPF produces reliable, high-quality forecasts [14]. As pointed out in [27], this is difficult as maritime spare parts are characterized by intermittent or lumpy demand patterns $[19,27]$. As a consequence, forecasting methods should be adapted to such characteristics. In fact, we find some adequate methods within statistical as well as machine learning as well as heuristics dealing with such demand patterns $[6,11,15,24]$.

Combinations of exponential smoothing techniques for group-level (item) time series are proposed in [19] for maritime spare parts. The objective is to determine the nature of spare parts demand, compare the performance of different forecasting methods, so that a model can be proposed that minimizes inventory costs. They reveal that spare parts item demand is lumpy, but less pronounced on group level and the best method to predict demand is a simple forecast combination using quarterly aggregate data adjusted for linear trend at group level as well as monthly aggregate unadjusted data at item level.

3.1.4. Spare Parts Inventory Control Inventory control is tightly linked to inventory management and deals with regulating on-hand inventory in a location, e.g., warehouse or distribution center whereas inventory management encompasses forecasting and sourcing of inventory and thus takes a broader perspective. The terms are often used interchangeably. Due to space reasons, we treat these two topics together with inventory location design and planning (ILDP). The latter further includes strategic decisions on where to place and inventory location and derives from network design and the inventory planning part involves which items to locate in which location.

The work of [27] deals with the selection of inventory facilities and the analysis which factors mostly influence the selection. The authors use AHP, factor rating method, as well as sensitivity analysis for their study. The objective is to determine the best location for a maritime spare parts distribution center in Sri 
Lanka. They determine the main factors achieved during interview as being 1) demand for spare parts, 2) time constraints, i.e., lead times, 3 ) proximity to international trade routes, 4) port clearance charges, 5) available facilities in port for spare parts handling and storage. The method seems useful, but the authors emphasize that changes in the demand factor impose significant effects on the result thus highlighting the importance of accurate demand forecasts.

\subsection{Joint Maintenance and Spare Parts Inventory Planning}

The overall goal of joint joint maintenance and spare parts planning (JMSPP) is to keep ship performance time as long as possible thus minimizing ship downtime. Downtimes are due to unexpected events corrupting its utilization, but also periodic maintenance in dry docks enforce downtime. This downtime can be extended by waiting times for spare parts if the replenishment lead time (LT) is longer than the begin of the scheduled maintenance action or the happening of an unexpected failure. The second goal is to achieve minimum downtimes by reduced overall maintenance costs including SPL.

The literature on joint (condition-based) maintenance and spare parts inventory management in various areas is rich (see the work presented in [37] and the references therein). Various different systems with a variety of complexity degrees are analyzed and presented. However, this topic is rarely treated within maritime shipping in the light of its specific situation.

The most comprehensive study concerning our problem area in bulk shipping is provided in [14]. The authors develop a model for integrated spare parts ordering and maintenance scheduling applying CBM for liner shipping cargo operations implying fixed routes and schedules. The model assumes that the parts can be send to the relevant port where maintenance operations are carried out after receipt of the parts. Spare parts can also be send directly to the ship by air freight, but the authors exclude this possibility in their model due to prohibitive high transportation costs. Different lead times to ports apply. The objective of their model is to minimize the costs due to delay and waiting times of the ship at the port for spare parts and costs associated to the procurement and maintenance process. Thus, the problem is where to order/send and pick-up the spare parts as soon as an identification to failure arises. Due to the different lead times, waiting times at the port can arise or ship system failure on route to the pick-up port if the item is send to another port other than the next. Remember that the schedule including port visit times is fixed. In that case, the ship is assumed still operational with a backup system, but must sail at slower speed. The authors provide a numerical analysis with 30 port calls conducted by one vessel and synthetic data. They use Monte-Carlo simulation for the engine parts malfunctions. Their results show that CBM systems can lead to great reduction in delay and improve punctuality of the ship, but cost reductions are dependent on the accuracy of the failure prediction in terms of remaining part lifetime and replenishment lead time.

\subsection{Spare Parts Delivery}

We find one reference in the literature that deals with optimal spare parts delivery to ships [35]. They develop a mathematical model to select the cost minimal transportation and shipment mode and test it on a medium-range product tanker considering three different spare part groups (main diesel engine, separator spares, fire, bilge and GS pump spares). Three different transportation modes are available: regular, express, and mixed variants with air transport. They conclude that the time variable has significant impact on the selection of the delivery mode.

\section{Discussion and Practical Guideline}

Challenges in SPL accrue due to the uncertainties regarding the planning situation with respect to failure rates and ship locations, component characteristics including criticality definitions, demand patterns, replenishment and logistics costs. For that reason, timing and allocation of spare parts is a challenging endeavor. For instance, if ship positions can be predicted together with failure rates of certain parts, it becomes possible to best allocate spare parts within the network. To date and to the best of our knowledge, we have not found any research dealing with this specific problem. Some research is ongoing to deal with condition-based monitoring of main ship engines (see [4, 16, 32]), but this has not been linked to SPL. A promising approach includes approximate dynamic programming (ADP) that encompasses modeling and algorithmic strategies for dealing with large and complex problems that are usually stochastic [23]. It has already been applied to maritime fleet management [21]. We expect this methodology to help dealing with the problem complexity in applying a rolling horizon technique to forecast future events and make best decisions based on the predicted system state.

Besides, also organizational issues that need to be in place before considering optimizing and controlling spare parts for ship maintenance. Based on our experience with bulk shipping companies within a 
Table 1. Classification of Approaches for Maritime Shipping.

\begin{tabular}{|c|c|c|c|c|c|c|}
\hline Source & Problem Area & Model & Objective & Solution Method & Case Study & Comments \\
\hline [9] & Review & n.a. & n.a. & n.a. & n.a. & $\begin{array}{l}\text { comprehensive } \\
\text { overview }\end{array}$ \\
\hline [2] & $\begin{array}{l}\text { Maintenance } \\
\text { scheduling }\end{array}$ & $\begin{array}{l}\text { non-linear, Markov } \\
\text { process }\end{array}$ & $\begin{array}{l}\text { cost of maintenance, } \\
\text { operations, downtime, penalty } \\
\text { for exceeding planned } \\
\text { intervals }\end{array}$ & optimization & $\begin{array}{l}\text { maritime: liquid } \\
\text { ring primer of bilge } \\
\text { system }\end{array}$ & $\begin{array}{ll}\text { deterioration } & \text { of } \\
\text { components; } & \text { no } \\
\text { SPL } & \end{array}$ \\
\hline [13] & $\begin{array}{l}\text { Maintenance } \\
\text { scheduling }\end{array}$ & SOHRA & minimize human error & SOHRA & diesel generator & $\begin{array}{l}\text { PMS based on } \\
\text { maintenance } 4.0\end{array}$ \\
\hline [32] & $\begin{array}{l}\text { Predictive } \\
\text { maintenance }\end{array}$ & prognostic model & predict failure rate & prognosis & $\begin{array}{l}\text { cylinder liners of a } \\
\text { diesel engine, } \\
\text { printed circuit } \\
\text { boards in radar } \\
\text { system }\end{array}$ & \\
\hline [4] & $\mathrm{CBM}$ & neural networks & $\begin{array}{l}\text { determine engine's fuel } \\
\text { consumption and faulty } \\
\text { conditions }\end{array}$ & machine learning & $\begin{array}{l}\text { Medium-speed } \\
\text { diesel engines }\end{array}$ & \\
\hline [16] & $\begin{array}{l}\text { Critical part } \\
\text { selection }\end{array}$ & $\begin{array}{l}\text { reliability } \\
\text { assessment }\end{array}$ & predict failure rates & $\begin{array}{l}\text { case scenario } \\
\text { analysis }\end{array}$ & $\begin{array}{l}\text { ship structure and } \\
\text { machinery } \\
\text { equipment } \\
\text { assessment }\end{array}$ & \\
\hline [19] & $\begin{array}{l}\text { On-board } \\
\text { spare parts } \\
\text { forecasting }\end{array}$ & $\begin{array}{l}\text { exponential } \\
\text { smoothing }\end{array}$ & minimize inventory costs & $\begin{array}{l}\text { exponential } \\
\text { smoothing and } \\
\text { simulation }\end{array}$ & South Korean Navy & \\
\hline [30] & $\begin{array}{l}\text { On-board } \\
\text { spare part } \\
\text { allocation }\end{array}$ & $\begin{array}{l}\text { TOPSIS, AHP, } \\
\text { non-linear model }\end{array}$ & $\begin{array}{l}\text { maximization of spare parts } \\
\text { availability }\end{array}$ & genetic algorithm & Chinese Navy & \\
\hline [20] & $\begin{array}{l}\text { On-board } \\
\text { spare part } \\
\text { control }\end{array}$ & $\begin{array}{l}\text { continuous-time } \\
\text { optimization }\end{array}$ & $\begin{array}{l}\text { minimize total costs of } \\
\text { inventory holding and item } \\
\text { unavailability }\end{array}$ & heuristic & $\begin{array}{l}\text { medium-sized } \\
\text { tanker }\end{array}$ & \\
\hline [27] & $\begin{array}{l}\text { Inventory } \\
\text { Management }\end{array}$ & $\begin{array}{l}\text { facility location } \\
\text { selection }\end{array}$ & Multi-criteria selection & $\begin{array}{l}\text { Selection } \\
\text { procedure; AHP }\end{array}$ & $\begin{array}{l}\text { distribution center } \\
\text { in Sri Lanka }\end{array}$ & $\begin{array}{l}\text { mixed } \\
\text { qualitative-quantitative } \\
\text { approach }\end{array}$ \\
\hline [14] & JMSPP & Simulation & $\begin{array}{l}\text { minimize costs due to delay } \\
\text { and waiting time }\end{array}$ & $\begin{array}{l}\text { Monte-Carlo } \\
\text { simulation }\end{array}$ & liner shipping & $\begin{array}{l}\text { different } \\
\text { replenishment } \\
\text { LT }\end{array}$ \\
\hline [35] & $\begin{array}{l}\text { Spare parts } \\
\text { delivery }\end{array}$ & linear program & $\begin{array}{l}\text { minimize total parcel delivery } \\
\text { costs, delivery time, and } \\
\text { distance between network } \\
\text { nodes }\end{array}$ & - & $\begin{array}{l}\text { medium-range } \\
\text { product tanker, } \\
\text { three spare parts } \\
\text { groups for main } \\
\text { diesel engine }\end{array}$ & $\begin{array}{l}\text { delivery modes: } \\
\text { regular, express, } \\
\text { mixed }\end{array}$ \\
\hline
\end{tabular}

research project, the following topics need careful consideration. For instance, data quality issues mainly influence analysis on SPL. We can confirm the points made in $[13,33]$ that the selection of key information from a rich knowledge base of experts is tough, but necessary to derive the right information that can be further processed for use in decision support tools for maintenance and related SPL. Informed and trained personnel is more willing to accurately gather data on maintenance jobs and spare parts utilization to be further used in inventory control and SPL. Moreover, shipping companies are generally equipped with ship management software supporting, a.o., maintenance and procurement actions and serving as PMS. Yet, such software is mostly designed to support the overall management of ship fleets with comparison to enterprise resource planning (ERP) systems for manufacturing companies providing master data management and specific departmental functionalities. Advanced optimization and decision support especially regarding network-related decisions is usually missing. The same is valid for personnel trained in sophisticated forecasting and optimization methods.

Most companies use preventive maintenance scheduled with the support of PMS. This reactive strategy leads to high SPL costs and related maintenance including a high portion of 1) maintenance jobs performed earlier than their due date, 2) high frequency of orders causing enhanced administrative and logistical costs, 4) $10 \%$ of urgent orders of overall orders within five years time frame. Shipping companies further struggle with determining overall maintenance costs to forecast future yearly fleet maintenance budgets. According to Figure 2, we recommend bulk shipping companies to follow the presented steps for establishing a JMSPP: 1) establish a predictive maintenance policy, 2) select critical parts on system or component level, 3) derive ship components failure rates either based on data-driven analysis which requires a PMS with high-quality data, 4) analyze critical item demand patterns to determine item quantities, 5) analyze and determine fleet location areas for bulk carriers to be able to allocate spare parts in the vicinity of frequent port 
calls, 6) establish warehouse locations for spare parts and manage/control spare parts inventories with support of specific ICT.

\section{Conclusion and Outlook}

The literature on maritime SPL management is rare which may be due to the uncertainties pertaining to the overall planning situation especially in bulk shipping, but surprising considering its importance concerning its share in trade volumes and the possibilities to optimize operational costs. Approaches exist that deal with specific parts of the overall problem. We also find some approaches jointly considering maintenance scheduling and SPL. Nevertheless, this problem area has not achieved enough interest from the research community and shipping companies are struggling with determining optimal spare parts allocation and inventory control that permits them to reduce operational costs of their fleet. We provide an overview of the overall problem area and some guideline on where to start in terms of organizational as well as data related issues in order to set up a successful system for SPL optimization.

\section{References}

[1] H. Ab-Samat and S. Kamaruddin. Opportunistic maintenance $(\mathrm{OM})$ as a new advancement in maintenance approaches. Journal of Quality in Maintenance Engineering, 20(2):98-121, may 2014.

[2] K.B Artana and K. Ishida. Spreadsheet modeling of optimal maintenance schedule for components in wear-out phase. Reliability Engineering \& System Safety, 77(1):81-91, jul 2002.

[3] A. Bacchetti and N. Saccani. Spare parts classification and demand forecasting for stock control: Investigating the gap between research and practice. Omega, 40(6):722-737, dec 2012.

[4] O.C. Basurko and Z. Uriondo. Condition-based maintenance for medium speed diesel engines used in vessels in operation. Applied Thermal Engineering, 80:404-412, apr 2015.

[5] M. Behzadian, S. Khanmohammadi Otaghsara, M. Yazdani, and J. Ignatius. A state-of the-art survey of TOPSIS applications. Expert Systems with Applications, 39(17):13051-13069, dec 2012.

[6] P. Berling and J. Marklund. A model for heuristic coordination of real life distribution inventory systems with lumpy demand. European Journal of Operational Research, 230(3):515-526, nov 2013.
[7] ClassNK. International management code for the safe operation of ships and for pollution prevention (international safety management (ism) code). Internet Source:https://www. classnk.or. $\mathrm{jp} / \mathrm{hp} / \mathrm{pdf} /$ activities/statutory/ ism/ ISM $\backslash$ _Cd/ISM-Code-e.pdf; last call 12.06.2021, 2015.

[8] C.D. Dao and M.J. Zuo. Selective maintenance for multi-state systems considering the benefits of repairing multiple components simultaneously. In Lecture Notes in Mechanical Engineering, pages 413-425. Springer International Publishing, nov 2014.

[9] A.S. Eruguz, T. Tan, and G.-J. van Houtum. A survey of maintenance and service logistics management: Classification and research agenda from a maritime sector perspective. Computers \& Operations Research, 85:184-205, sep 2017.

[10] G. Galante and G. Passannanti. An exact algorithm for preventive maintenance planning of series-parallel systems. Reliability Engineering \& System Safety, 94(10):1517-1525, oct 2009.

[11] R.S. Gutierrez, A.O. Solis, and S. Mukhopadhyay. Lumpy demand forecasting using neural networks. International Journal of Production Economics, 111(2):409-420, feb 2008.

[12] IACS. Classification societies - what, why and how? Internet Source: https: //www.iacs.org.uk/media/7425/ classification-what-why-how.pdf; last call 12.06.2021, 2020. IACS Information Paper.

[13] C. Kandemir and M. Celik. A human reliability assessment of marine auxiliary machinery maintenance operations under ship PMS and maintenance 4.0 concepts. Cognition, Technology \& Work, 22(3):473-487, aug 2019.

[14] R. Kian, T. Bektaş, and D. Ouelhadj. Optimal spare parts management for vessel maintenance scheduling. Annals of Operations Research, 272(1-2):323-353, jun 2018.

[15] D. Kiefer, F. Grimm, M. Bauer, and D. van Dinther. Demand forecasting intermittent and lumpy time series: Comparing statistical, machine learning and deep learning methods. In Proceedings of the 54th Hawaii International Conference on System Sciences. Hawaii International Conference on System Sciences, 2021.

[16] I. Lazakis, K. Dikis, A. Lito Michala, and 
G. Theotokatos. Advanced ship systems condition monitoring for enhanced inspection, maintenance and decision making in ship operations. Transportation Research Procedia, 14:1679-1688, 2016.

[17] C. Lundgren, J. Bokrantz, and A. Skoogh. A strategy development process for smart maintenance implementation. Journal of Manufacturing Technology Management, 32(9):142-166, apr 2021.

[18] F.P García Márquez, A.M. Tobias, J.M.P. Pérez, and M. Papaelias. Condition monitoring of wind turbines: Techniques and methods. Renewable Energy, 46:169-178, oct 2012.

[19] S. Moon, C. Hicks, and A. Simpson. The development of a hierarchical forecasting method for predicting spare parts demand in the south korean navy-a case study. International Journal of Production Economics, 140(2):794-802, dec 2012.

[20] M.E. Nenni and M.M. Schiraldi. Optimizing spare parts inventory in shipping industry. International Journal of Engineering and Technology, 5(3):3152-3157, 2013.

[21] Dimitri J. Papageorgiou, Myun-Seok Cheon, George Nemhauser, and Joel Sokol. Approximate dynamic programming for a class of long-horizon maritime inventory routing problems. Transportation Science, 49(4):870-885, nov 2015.

[22] S.C. Pirrong. Contracting practices in bulk shipping markets: A transactions cost explanation. The Journal of Law \& Economics, 36(2):937-976, 1993.

[23] Warren B. Powell. What you should know about approximate dynamic programming. Naval Research Logistics (NRL), 56(3):239-249, feb 2009.

[24] A. Regattieri, M. Gamberi, R. Gamberini, and R. Manzini. Managing lumpy demand for aircraft spare parts. Journal of Air Transport Management, 11(6):426-431, nov 2005.

[25] I. Roda, M. Macchi, L. Fumagalli, and P. Viveros. A review of multi-criteria classification of spare parts. Journal of Manufacturing Technology Management, 25(4):528-549, apr 2014.

[26] R. Scarsi. The bulk shipping business: market cycles and shipowners' biases. Maritime Policy \& Management, 34(6):577-590, dec 2007.
[27] H.O. Sirisena and N.A. Samarasekera. Vessel spare parts distribution center location decision model for ship maintenance supply chain. In 2018 IEEE International Conference on Service Operations and Logistics, and Informatics (SOLI). IEEE, jul 2018.

[28] L. Stazić, I. Komar, L. Mihanović, and A. Mišura. Shipowner's impact on planned maintenance system database quality grades resemblance equalization. Transactions on Maritime Science, 7(1):5-22, apr 2018.

[29] M. Stopford. Maritime Economics. Routledge, 3 edition, 2009.

[30] Z. Tang, M.-C. Lin, and C.Y. Wang. Critical evaluation and optimal allocation model of ship spare parts. In 4th International Conference on Modelling, Simulation and Applied Mathematics (MSAM 2020), pages 191-200, 2020. ISBN: 978-1-60595-674-9.

[31] R.H. Teunter, M. Zied Babai, and A.A. Syntetos. ABC classification: Service levels and inventory costs. Production and Operations Management, 19(3):343-352, nov 2009.

[32] T. Tinga, W. Tiddens, F. Amoiralis, and M. Politis. Predictive maintenance of maritime systems: Models and challenges. In Safety and Reliability - Theory and Applications. CRC Press, jun 2017.

[33] O. Turan, A. İ. Ölçer, I. Lazakis, P. Rigo, and J. D. Caprace. Maintenance/repair and production-oriented life cycle cost/earning model for ship structural optimisation during conceptual design stage. Ships and Offshore Structures, 4(2):107-125, may 2009.

[34] United Nations. Review of maritime transport 2020. Internet Source: https://unctad.org/webflyer/review-maritime-transport-2020, 2020. last call 09.06.2021.

[35] L. Vukić, L. Stazić, M. Pijaca, and I. Peronja. Modelling the optimal delivery of spare parts to vessels: Comparison of three different scenarios. Cogent Engineering, 8(1):1920565, jan 2021.

[36] R.Q Zhang, H.J. Wallace, and C. Supatgiat. Spreadsheet implementable inventory control for a distribution center. Journal of Heuristics, 7(2):185-203, 2001.

[37] X. Zhang and J. Zeng. Joint optimization of condition-based opportunistic maintenance and spare parts provisioning policy in multiunit systems. European Journal of Operational Research, 262(2):479-498, oct 2017. 